\title{
The relationship between fertility and intermediate optimum type traits in Polish Holstein-Friesian cows
}

\author{
W. Jagusiak ${ }^{1,3}$, E. Ptak ${ }^{1}$, A. Żarnecki ${ }^{2}$ and A. Satoła ${ }^{1}$ \\ 1 University of Agriculture in Krakow, Department of Genetics and Animal Breeding, Al. Mickiewicza 24/28, 30-059 Kraków, Poland \\ ${ }^{2}$ National Research Institute of Animal Production, 32-083 Balice, Poland
}

KEY WORDS: type traits, fertility traits, frtility indicators, genetic parameters, dairy cattle
Received: 22 June 2012

Revised: 31 January 2014

Accepted: 4 March 2014

${ }^{3}$ Corresponding author: e-mail: rzjagusi@cyfronet.pl

\begin{abstract}
The purpose of this study was to find early indicators of cow fertility. Genetic correlations of two types of conformation evaluations, routine and modified, with reproduction traits were estimated. Data consisted of type evaluations and fertility measures of primiparous Holstein-Friesian cows born from 2005 to 2006. The number of records ranged between 4731 and 8041 depending on the trait. Type traits with intermediate optima were evaluated using routine and modified scales. In the modified system, the more desirable form of a trait received the higher score. A multi-trait animal model and Gibbs sampling were applied. Among modified type traits the highest genetic correlations were found between non-return rates for cows and rear legs side view $(-0.36)$, between days open and rump angle (0.36), and between interval from calving to first insemination and rump angle (0.35). Genetic correlations of routine type traits with fertility measures were low for udder traits and rump angle $(-0.08$ to $0.10)$ and moderate for leg traits $(-0.34$ to 0.44$)$ and body depth ( -0.41 to 0.36 ). Modified scores for rear legs side view and rump angle, and routine scores for body depth and foot angle may be used as early indicators of cow fertility in Polish Holstein-Friesians.
\end{abstract}

\section{Introduction}

The decline in fertility seen in recent years can be attributed partly to changes in some conformation traits (Shapiro and Swanson, 1991). The genetic correlations between intermediate optimum type traits and fertility reported by many authors vary in value and direction. Pryce et al. (2000) reported that calving interval was genetically correlated relatively highly with body depth $(0.26)$ and moderately with rear leg set (0.19), foot angle $(-0.20)$ and fore udder attachment $(-0.17)$. Genetic correlations of calving interval with udder depth and rump angle were low ( -0.13 and 0.07 , respectively). According to the results obtained by Dal Zotto et al. (2007), calving interval was genetically correlated with body depth (0.10), rump angle (0.24), fore udder attachment (0.14) and udder depth (0.23). Wall et al. (2005) estimated genetic correlations between rump angle and calving interval, days to first service and nonreturn rates until the $56^{\text {th }}$ day and obtained -0.16 , 0.09 and -0.01 , respectively.

The routine evaluation system for type traits in Poland is based on a linear scale ranging from 1 to 9 . The highest and lowest values of the scale are related to biological extrema, whereas the average values correspond to the most frequent forms of traits. This scale does not reflect desirability because 
the form of some traits considered by breeders as optimal is related to the value in the middle of the scale. Moreover, an intermediate optimum makes correlations difficult to interpret.

In this study, a modified scale for traits with intermediate optima was proposed in which the more desirable form of the trait is always related to a higher score. The purpose of this study was to identify type measures useful for early prediction of cow fertility; therefore, genetic correlations of linear routine and modified type evaluations with reproduction traits were estimated.

\section{Material and methods}

Data consisted of type evaluations and fertility measures of primiparous Holstein-Friesian cows born from 2005 to 2006 on large farms involved in the AI testing scheme. The number of type records was 8041 and that for fertility traits ranged between 4731 and 7379 , depending on the trait.

All cows calved in 2008 in 828 herds and were evaluated between the $15^{\text {th }}$ and $180^{\text {th }}$ days of lactation by four classifiers. The following restrictions were imposed: sires with more than 5 daughters, and groups of contemporaries with at least 3 cows. The final file consisted of 8041 cows, daughters of 359 sires. The average number of daughters per sire was 22.4. Most sires had from 10 to 49 daughters (78\%) and only 22 sires had 50 or more daughters. The mean number of cows per herd was 9.7, and almost $22 \%$ of the cows came from herds with 3 to 5 contemporaries. All cows were classified in 1,110 herd-year-season-classifier subclasses (HYSC) of which $65 \%$ comprised 3 to 6 cows. Two seasons of calving were defined: April to September and October to March. Based on the dates of calving and type evaluation, each cow was assigned to one of 11 stages of lactation (15 days per stage).

Six type traits with intermediate optima (body depth, rump angle, rear legs side view, foot angle, fore udder height and udder depth) were evaluated by classifiers who used routine and modified scales, both based on a linear scale from 1 to 9 . In the modified evaluation system, the more desirable form of a trait received the higher score, whereas the more undesirable form received a lower score. For example, in the routine system the most desirable score for rump angle is 5 . In the modified system, cows with optimal routine score for rump angle received 9 and cows with routine score lower or higher than 5 received less than 9 according to the classifier's decision. No function was applied to transform routine to modified scores. Five descriptive conformation traits scored on a scale from 50 to 90 were also included in the analysis. The descriptive statistics of routine and modified scores are shown in Table 1.
Table 1. Descriptive statistics and heritabilities of conformation and fertility traits

\begin{tabular}{lrrrrr}
\hline \multirow{2}{*}{ No. Trait } & $\bar{x}$ & \multirow{2}{*}{ SD } & \multicolumn{2}{l}{ Skew- } \\
\cline { 5 - 7 } & & & \multicolumn{2}{l}{ Heritability } \\
\cline { 5 - 7 } Descriptive conformation traits & & & & $h^{2}$ & $S D$ \\
1. Size & 81.6 & 5.5 & -0.85 & 0.53 & 0.06 \\
2. Conformation and dairy character & 79,1 & 4.4 & -0.64 & 0.40 & 0.05 \\
3. Overall feet and legs & 78.9 & 4.1 & -0.81 & 0.13 & 0.03 \\
4. Overall udder & 77.3 & 5.1 & -1.83 & 0.19 & 0.03 \\
5. Overall conformation score & 78.5 & 3.9 & -0.88 & 0.28 & 0.04 \\
6. Stature & 143.1 & 4.3 & -0.18 & 0.59 & 0.06 \\
Routine linear conformation traits & & & & \\
7. Body depth & 5.9 & 1.4 & -0.44 & 0.32 & 0.04 \\
8. Rump angle & 5.0 & 1.2 & 0.14 & 0.39 & 0.05 \\
9. Rear legs side view & 5.4 & 1.2 & -0.09 & 0.23 & 0.03 \\
10. Foot angle & 5.1 & 1.4 & -0.04 & 0.16 & 0.03 \\
11. Fore udder height & 5.5 & 1.4 & -0.27 & 0.35 & 0.04 \\
12. Udder depth & 5.4 & 1.6 & -0.23 & 0.44 & 0.05 \\
Modified linear conformation traits & & & & \\
13. Body depth & 7.3 & 1.7 & -0.50 & 0.12 & 0.02 \\
14. Rump angle & 7.7 & 1.6 & -0.32 & 0.09 & 0.02 \\
15. Rear legs side view & 7.4 & 1.8 & -0.15 & 0.14 & 0.03 \\
16. Foot angle & 5.6 & 1.8 & -0.21 & 0.15 & 0.02 \\
17. Fore udder height & 6.3 & 1.9 & -0.37 & 0.30 & 0.03 \\
18. Udder depth & 6.5 & 2.0 & -0.23 & 0.31 & 0.04 \\
Fertility traits & & & & & \\
19. NRh & 0.78 & 0.42 & - & 0.06 & 0.04 \\
20. NRc & 0.63 & 0.48 & - & 0.12 & 0.04 \\
21. ICF & 93,8 & 40.2 & 1.19 & 0.15 & 0.03 \\
22. DO & 131.8 & 64.1 & 0.96 & 0.14 & 0.03 \\
\hline
\end{tabular}

${ }^{1}$ non-return rates until $56^{\text {th }}$ day after insemination for heifers

${ }^{2}$ non-return rates until $56^{\text {th }}$ day after insemination for primiparous cows 3 interval from calving to first insemination

${ }^{4}$ days open

Presently, four reproduction traits are included in the Polish evaluation system. Measures of ability to conceive are non-return rates until the $56^{\text {th }}$ day after insemination for heifers (NRh) and primiparous cows (NRc). Interval from calving to first insemination (ICF) for first-parity cows is a measure of the ability to recycle, and days open (DO) is a combined interval trait. Non-return rates were defined as binary traits. If a cow showed oestrus within 56 days after insemination, then non-return rates (NRh and $\mathrm{NRc}$ ) were equal to zero; otherwise they were equal to one. Interval from calving to first insemination (ICF) was measured as the number of days between the date of first calving and the date of first insemination after this calving; days open were defined as the number of days between the date of first calving and the date of last insemination. Dates of inseminations were not available for each cow. Intervals shorter than 21 days were excluded; the longest accepted intervals were 250 days for ICF and 365 days for DO. The descriptive statistics and number of cows with computed fertility measures are shown in Table 1.

In the literature, there are two approaches for estimating genetic parameters for traits scored as 0 or 1 (like NRh and NRc): a linear or a threshold model. Hansen et al. (2004) estimated genetic parameters for stillbirth using both threshold and lin- 
ear approaches and found heritabilities estimated by the threshold model to be on average twice those obtained by the linear model; on the other hand, increased computing time is the main disadvantage of the threshold approach. Most of the traits analysed in this paper were normally distributed, so the linear model was used for all multi-trait estimations.

(Co)variance components of the type and fertility traits were estimated based on a Bayesian approach with Gibbs sampling (Tsuruta and Misztal, 2006) using the multi-trait linear model:

$$
\mathbf{y}=\mathbf{X b}+\mathbf{Z Q g}+\mathbf{Z u}+\mathbf{e}
$$

where: $\mathbf{y}$ - the vector of observations, $\mathbf{g}$ - the vector of fixed effects of genetic groups, $\mathbf{b}$ - the vector of fixed effects, $\mathbf{u}-$ the vector of additive animal genetic effects, $\mathbf{e}-$ the vector of residual error, $\mathbf{X}$, $\mathbf{Z}$ and $\mathbf{Q}$ - coincidence matrices. For type traits, vector b contains effects of HYSC, stage of lactation and regression on age at calving. For NRh and NRc, $\mathbf{b}$ comprises effects of herd-year of insemination, month of insemination and regression on age at insemination. For ICF and DO, vector $\mathbf{b}$ consisted of effects of herd-year of calving, month of calving, and regression on age at calving. Matrix $\mathbf{G}=\mathbf{A}^{-1} \mathbf{G}_{\mathbf{0}}$, where $\mathbf{A}^{-1}$ is a numerator relationship matrix and $\mathbf{G}_{\mathbf{0}}$, a genetic (co)variance matrix between traits. It was assumed that $\mathrm{E}(\mathbf{u})=\mathbf{0}, \mathrm{E}(\mathbf{e})=\mathbf{0}, \mathrm{V}(\mathbf{u})=\mathbf{G}$, $\mathrm{V}(\mathbf{e})=\mathbf{R}, \operatorname{Cov}(\mathbf{u}, \mathbf{e})=\mathbf{0}$, and $\mathrm{E}(\mathbf{y})=\mathbf{X b}+\mathbf{Z Q g}$, $\mathrm{V}(\mathbf{y})=\mathbf{Z G Z}+\mathbf{R}$. Matrix $\mathbf{R}=\mathbf{I} \otimes \mathbf{R}_{\mathbf{0}}$, where $\mathbf{R}_{\mathbf{0}}$ is a residual (co)variance matrix between traits.

Animals with unknown parents were assigned to genetic groups based on birth year and sex of the unknown parent (Westell et al., 1988).

Software based on the Gibbs sampling algorithm was used (Tsuruta and Misztal, 2006). There were 100,000 samples generated with the first 10,000 as a burn-in period. Estimated (co)variance components were used to calculate genetic parameters and their standard deviations. Standard deviations of the parameters were computed based on parameter values calculated within each sample.

\section{Results and discussion}

Type traits were scored for all 8,041 cows in the data file, whereas fertility measures were available for 7379 (NRh), 5724 (NRc), 5215 (DO) and 4731 (ICF) cows. Means, standard deviations, skewness and heritability for all analysed type and fertility traits are presented in Table 1.

Modified linear conformation traits showed higher means and standard deviations than routine ones. The biggest differences between average scores on routine and modified scales were obtained for traits with an optimum in the middle of the routine scale (e.g., for rump angle). For traits with an optimum close to 7 , the differences between both types of scores were lower (e.g., for foot angle).

Among fertility traits, variation was lower for ICF and DO than for NRh and NRc. Asymmetry coefficients for all conformation traits were negative, indicating that more observations were located on the left side of the mode, especially in the case of descriptive traits. Among linear type traits (routine and modified) the greatest asymmetry was noted for body depth. The distributions of ICF and DO were strongly skewed. In both cases the coefficients of asymmetry were positive, i.e. with longer tails on the right side of the distributions. Similar statistics for NRc and ICF were reported by Veerkamp et al. (2001) and Wall et al. (2005), whereas Pryce et al. (2001), Kadarmideen (2004) and Zink et al. (2011) obtained mean ICF of less than 81 days.

Among descriptive type traits, size was the most heritable trait, and feet and legs, the least heritable. Routine linear traits showed relatively high heritabilities (0.16-0.44). All estimates of heritability for linear traits were higher than previous Polish estimates (Ptak et al., 2009) and those reported by Dal Zotto et al. (2007). The heritabilities for modified type scores were lower than for routine scores. The largest differences between the two were in traits with optima in the middle of the scale (i.e. 5 points). For example, in the case of rump angle the heritability of routine scores was found to be more than 4 times as high as for that of modified scores. For traits with an optimum close to 8 points, the heritabilities for modified scores were similar to those for routine traits.

The heritabilities of fertility measures ranged between 0.06 for NRh and 0.15 for ICF, and were higher than previous Polish estimates (Jagusiak, 2005a,b). Much lower estimates were reported by Wall et al. (2005): 0.05 for days to first service and 0.014 for non-return rate to $56^{\text {th }}$ day. Liu et al. (2008) also presented heritabilities of fertility traits lower than ours: $0.012,0.015,0.039$ and 0.026 for NRh, NRc, ICF and DO, respectively. The difference between the estimates obtained in this study and those of Wall et al. (2005) and Liu et al. (2008) might be the result of methodological differences.

The genetic correlations between routine linear traits and fertility measures were weak for udder traits and rump angle and moderate for leg traits and body depth (Table 3 ). The positive genetic correlation between rear legs side view and ICF means that selection for straight legs shortens intervals from 
Table 2. Genetic $\left(r_{\mathrm{g}}\right)$ and phenotypic $\left(r_{\mathrm{p}}\right)$ correlations between modified linear conformation and fertility traits

\begin{tabular}{|c|c|c|c|c|c|c|c|c|}
\hline \multirow{2}{*}{ Trait } & \multicolumn{4}{|c|}{$r_{g}$} & \multicolumn{4}{|c|}{$r_{\mathrm{p}}$} \\
\hline & $\mathrm{NRh}^{1}$ & $\mathrm{NRc}^{2}$ & $\mathrm{ICF}^{3}$ & $\mathrm{DO}^{4}$ & $\mathrm{NRh}^{1}$ & $\mathrm{NRc}^{2}$ & $\mathrm{ICF}^{3}$ & $\mathrm{DO}^{4}$ \\
\hline Body depth & -0.15 & -0.33 & -0.12 & -0.11 & 0.02 & -0.01 & -0.02 & -0.01 \\
\hline Rump angle & -0.07 & -0.25 & 0.35 & 0.36 & -0.03 & 0.00 & -0.03 & -0.01 \\
\hline Rear legs side view & 0.06 & -0.36 & -0.33 & -0.07 & 0.01 & -0.01 & -0.04 & -0.01 \\
\hline Foot angle & -0.08 & -0.20 & 0.32 & 0.21 & -0.01 & 0.00 & -0.02 & -0.01 \\
\hline Fore udder height & 0.07 & -0.07 & -0.02 & 0.11 & 0.01 & 0.04 & -0.01 & -0.04 \\
\hline Udder depth & 0.15 & -0.15 & 0.05 & 0.18 & 0.01 & 0.03 & -0.02 & -0.04 \\
\hline
\end{tabular}

SD for $r_{\mathrm{g}}$ ranged from 0.16 to 0.36 and for $r_{\mathrm{p}}$ from 0.01 to $0.02 ;{ }^{1}$ non-return rates until $56^{\text {th }}$ day after insemination for heifers; ${ }^{2}$ non-return rates until $56^{\text {th }}$ day after insemination for primiparous cows; ${ }^{3}$ interval from calving to first insemination; ${ }^{4}$ days open

Table 3. Genetic $\left(r_{g}\right)$ and phenotypic $\left(r_{p}\right)$ correlations between routine linear conformation and fertility traits

\begin{tabular}{|c|c|c|c|c|c|c|c|c|}
\hline \multirow{2}{*}{ Trait } & \multicolumn{4}{|c|}{$r_{g}$} & \multicolumn{4}{|c|}{$r_{p}$} \\
\hline & $\mathrm{NRh}^{1}$ & $\mathrm{NRc}^{2}$ & $\mathrm{ICF}^{3}$ & $\mathrm{DO}^{4}$ & $\mathrm{NRh}^{1}$ & $\mathrm{NRc}^{2}$ & $\mathrm{ICF}^{3}$ & $\mathrm{DO}^{4}$ \\
\hline Body depth & 0.08 & -0.41 & 0.26 & 0.36 & 0.00 & -0.02 & -0.01 & 0.02 \\
\hline Rump angle & -0.08 & 0.01 & 0.10 & -0.05 & -0.02 & 0.01 & 0.02 & 0.02 \\
\hline Rear legs side view & -0.26 & 0.21 & 0.14 & -0.14 & -0.01 & 0.03 & 0.04 & 0.03 \\
\hline Foot angle & -0.22 & -0.34 & 0.44 & 0.31 & -0.01 & 0.00 & -0.03 & -0.02 \\
\hline Fore udder height & 0.01 & -0.02 & 0.01 & 0.10 & 0.01 & 0.04 & -0.01 & -0.04 \\
\hline Udder depth & 0.06 & -0.03 & -0.08 & -0.03 & 0.01 & 0.03 & -0.01 & -0.04 \\
\hline
\end{tabular}

SD for $r_{\mathrm{g}}$ ranged from 0.10 to 0.21 and for $r_{\mathrm{p}}$ from 0.01 to $0.02 ;{ }^{1}$ non-return rates until $56^{\text {th }}$ day after insemination for heifers; ${ }^{2}$ non-return rates until $56^{\text {th }}$ day after insemination for primiparous cows; ${ }^{3}$ interval from calving to first insemination; ${ }^{4}$ days open

Table 4. Genetic $\left(r_{\mathrm{g}}\right)$ and phenotypic $\left(r_{\mathrm{p}}\right)$ correlations between descriptive conformation and fertility traits

\begin{tabular}{|c|c|c|c|c|c|c|c|c|}
\hline \multirow{2}{*}{ Trait } & \multicolumn{4}{|c|}{$r_{g}$} & \multicolumn{4}{|c|}{$r_{\mathrm{p}}$} \\
\hline & $\mathrm{NRh}^{1}$ & $\mathrm{NRC}^{2}$ & $\mathrm{ICF}^{3}$ & $\mathrm{DO}^{4}$ & $\mathrm{NRh}^{1}$ & $\mathrm{NRC}^{2}$ & $\mathrm{ICF}^{3}$ & $\mathrm{DO}^{4}$ \\
\hline Size & -0.05 & -0.28 & 0.03 & 0.30 & -0.03 & -0.01 & 0.00 & 0.03 \\
\hline Conformation and dairy character & 0.02 & -0.24 & 0.21 & 0.43 & 0.00 & -0.01 & 0.04 & 0.06 \\
\hline Overall feet and legs & -0.05 & -0.07 & -0.24 & -0.06 & 0.00 & 0.00 & -0.05 & 0.00 \\
\hline Overall udder & -0.11 & 0.05 & 0.07 & 0.02 & 0.01 & 0.01 & 0.03 & 0.02 \\
\hline Overall conformation score & -0.08 & -0.11 & 0.04 & 0.17 & 0.00 & 0.01 & 0.02 & 0.03 \\
\hline Stature & -0.03 & -0.23 & 0.01 & 0.26 & -0.03 & -0.01 & 0.02 & 0.04 \\
\hline
\end{tabular}

SD for $r_{g}$ ranged from 0.13 to 0.20 and for $r_{p}$ from 0.01 to $0.02 ;{ }^{1}$ non-return rates until $56^{\text {th }}$ day after insemination for heifers; ${ }^{2}$ non-return rates until $56^{\text {th }}$ day after insemination for primiparous cows; ${ }^{3}$ interval from calving to first insemination; ${ }^{4}$ days open

calving to first insemination. On the other hand, the negative correlation between rear legs and DO suggested selection for fewer days open results in sickled legs of cows in the population. The positive correlation of rear legs with ICF and negative with DO implied a shorter service period, which might be confirmed by the positive, favourable correlation between rear legs and NRc. These results partly agree with the findings of Zink et al. (2011), who reported a positive genetic correlation between rear legs and both ICF and DO, but differ from the values published by Onyiro et al. (2008), who obtained low negative correlations between rear legs and calving interval (CI) (0.09) and NRc (-0.11). $\mathrm{CI}$ and DO were closely related to each other because CI consisted of days open (DO) and gestation length and the latter showed very little variation (Jagusiak, 2005b). The correlations between CI and rear leg set reported by Pryce et al. (2000), Jagusiak (2005b) and Dal Zotto et al. (2007) were similar in magnitude but opposite in direction to those in this study.

Foot angle was unfavourably correlated with all fertility traits; a steeper foot angle was associated with lower NRh and NRc and longer intervals (ICF and DO), so selection for a steeper foot angle deteriorates all fertility measures. The correlations of foot angle with ICF and DO reported by Zink et al. (2011) were very low, whereas Onyiro et al. (2008) obtained a positive and also unfavourable genetic correlation of foot angle with CI (0.19) and a favourable correlation with NRc (0.14). 
The genetic correlation between body depth and NRc was negative and moderate; this means that daughters of bulls with a higher breeding value for body depth were also supposed to have a worse NRc. The large correlation between body depth and DO in this study was similar to that obtained by Pryce et al. (2000) and Dal Zotto et al. (2007) for body depth and CI, suggesting that selection for deep body will unfavourably affect ICF and DO.

Generally, selection for steeper foot and deep body leads to poorer reproduction (e.g., longer ICF and DO). Sickled legs were related favourably to DO but unfavourably to ICF. In turn, shallow body and low foot were associated with desired NRc. Heifers with straight legs, unlike cows, were predisposed to better NRh.

Among modified linear type traits, body depth, rump angle and leg traits showed moderate genetic correlations with NRc and ICF (Table 2). The highest unfavourable correlations were found between $\mathrm{NRc}$ with rear legs side view and body depth. For ICF and DO the genetic relationships with rump angle and foot angle were also adverse. A preferable moderate genetic correlation occurred between ICF and rear legs side view, indicating that cows with a high breeding value for rear legs were expected to have a shorter ICF. The genetic correlations between modified type traits and NRh were low.

Relatively weak genetic correlations were found between fertility measures and descriptive type traits: the strongest, but unfavourable, were for DO and NRc with conformation and dairy character, size and stature (Table 4). ICF was moderately undesirably correlated with conformation and dairy character and desirably with feet and legs. Correlations between NRh and descriptive type traits were negligible.

The genetic correlations of stature and feet and legs with fertility measures reported in the literature vary in magnitude and direction (Pryce et al., 2000; Zink et al., 2011; Dal Zotto et al., 2007; Onyiro et al., 2008). All reported correlations are smaller than the estimates obtained in this study, except for the correlation between stature and CI reported by Kadarmideen (2004).

All phenotypic correlations were close to zero (Tables 2-4).

In many cases the genetic relationships were higher between modified type traits and fertility traits than between routine type traits and fertility traits. The unfavourable correlations of modified type traits with fertility traits indicate that cows with conformation scores taken by classifiers as optima did not have high breeding values for fertility traits.

\section{Conclusions}

Generally, the routine system of type evaluation permitted prediction of cow fertility as efficiently as the modified system. Modified type traits were more genetically related to non-return rates until $56^{\text {th }}$ day after inseminatiom for primiparous cows, interval from calving to first insemination and days open than the routine type traits, but the optimal score for conformation did not show better fertility in all cases (e.g., foot angle). Both modified and routine type scores may be used as early indicators of cow fertility in the Polish population of Holstein Friesian cows so there is no need to implement the modified system of type evaluation.

\section{References}

Dal Zotto R., De Marchi M., Dalvit C., Cassandro M., Gallo L., Carnier P., Bittante G., 2007. Heritabilities and genetic correlations of body condition score and calving interval with yield, somatic cell score and linear type traits in Brown Swiss cattle. J. Dairy Sci. $90,5737-5743$

Hansen M., Lund M.S., Pedersen J., Christensen L.G., 2004. Genetic parameters for stillbirth in Danish Holstein cows using Bayesian threshold model. J. Dairy Sci. 87, 706-716

Jagusiak W., 2005a. Fertility measures in Polish Black-and-White cattle. 1. Genetic parameters of heifer fertility traits. J. Anim. Feed Sci. 14, 423-433

Jagusiak W., 2005b. Fertility measures in Polish Black-and-White cattle. 2. Genetic parameters of interval measures. J. Anim. Feed Sci. 14, 435-444

Kadarmideen H.N., 2004. Genetic correlations among body condition score, somatic cell score, milk production, fertility and conformation traits in dairy cows. Anim. Sci. 79, 191-201

Liu Z., Jaitner J., Reinhardt F., Pasman E., Rensing S., Reents R., 2008. Genetic evaluation of fertility traits of dairy cattle using a multiple-trait animal model. J. Dairy Sci. 91, 4333-4343

Onyiro M., Andrews L.J., Brotherstone S., 2008. Genetic parameters for digital dermatitis and correlations with locomotion, production, fertility traits, and longevity in Holstein-Friesian dairy cows. J. Dairy Sci. 91, 4037-4046

Pryce J.E., Coffey M.P., Brotherstone S., 2000. The genetic relationship between calving interval, body condition score and linear type and management traits in registered Holsteins. J. Dairy Sci. 83, 2664-2671

Pryce J.E., Coffey M.P., Simm G., 2001. The relationship between body condition score and reproductive performance. J. Dairy Sci. 84, 1508-1515

Ptak E., Jagusiak W., Żarnecki A., Otwinowska-Mindur A., 2009. Genetic parameters of daily somatic cell score and some conformation traits in Polish Holstein cattle. Ann. Anim. Sci. 9, 335-361

Shapiro L.S., Swanson L.V., 1991. Relationships among rump and rear leg type traits and reproductive performance in Holsteins. J.Dairy Sci. 74, 2767-2773

Tsuruta S., Misztal I., 2006. THRGIBBS1F90 for estimation of variance components with Threshold-linear Models. Proceedings of $8^{\text {th }}$ World Congress on Genetics Applied to Livestock Production, Belo Horizonte (Brazil). CD-ROM communication 27, 31

Veerkamp R.F., Koenen E.P.C., De Jong G., 2001. Genetic correlations among body condition score, yield, and fertility in first-parity 
cows estimated by random regression models. J. Dairy Sci. 84, 2327-2335

Wall E., White M.S., Coffey M.P., Brotherstone S., 2005. The relationship between fertility, rump angle and selected type information in Holstein-Friesian cows. J. Dairy Sci. 88, 1521-1528
Westell R.A., Quaas R.L., Van Vleck L.D., 1988. Genetic groups in an animal model. J. Dairy Sci. 71, 1310-1318

Zink V., Štipková M., Lassen J., 2011. Genetic parameters for female fertility, locomotion, body condition score and linear type traits in Czech Holstein cattle. J. Dairy Sci. 94, 5176-5182 